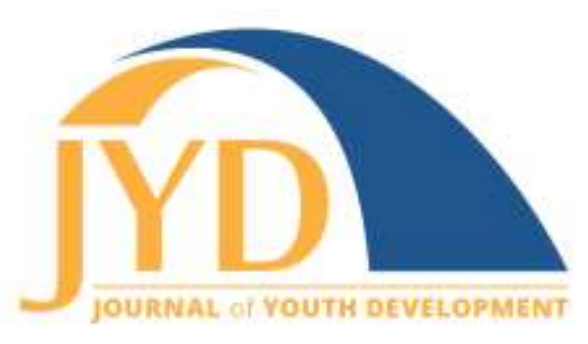

http://jyd.pitt.edu/ | Vol. 12 Issue 1 DOI 10.5195/jyd.2017.500 | ISSN 2325-4017 (online)

\title{
Correction to: MacDonnell, M., Urban, J.B., \& Linver, M.R. "A Mixed-Methods Exploration of Intentional Self Regulation and Youth Beliefs about the Chances of Achieving Future Aspirations." Journal of Youth Development, 10(3) 2015.
}

\author{
Kate Walker \\ University of Minnesota \\ kcwalker@umn.edu
}

http://dx.doi.org/10.5195/jyd.2015.11

\begin{abstract}
A series of edits to the text were made to remove or replace words. The authors added an acknowledgement of funding. Finally, the accent was removed from all references to Gestsdottir. The original article can be found via the DOI: http://dx.doi.org/10.5195/jyd.2015.11
\end{abstract}

\section{Erratum}

Page 103: Removed "such" so that the sentence reads, "In RDS metatheory, there is a rejection of reductionist and split conceptions, and a focus on bidirectional exchanges between individuals and contexts (Overton, 2015)."

Page 104: Replaced the word "provides" with "provide" so that the sentence reads, "In addition to allowing adolescents to serve as active agents in their own development, effective goal setting may also contribute to feelings of purpose and provide a sense of meaning (Freund \& Baltes, 2002)."

\footnotetext{
(cc) EY New articles in this journal are licensed under a Creative Commons Attribution 4.0 License. This journal is published by the University Library System, University of Pittsburgh and is cosponsored by the University of Pittsburgh Press. The Journal of Youth Development is the official peer-reviewed publication of the National Association of Extension 4-H Agents and the National AfterSchool Association.
} 
Page 104: Removed the words "Measures of" so that the sentence reads, "Selection, Optimization, and Compensation have been identified as separate constructs in adults (Gestsdottir, Bowers, von Eye, Napolitano, \& Lerner, 2010)."

Page 104: Removed the words "it may be that" so that the sentence reads, "Additional research is needed to better understand the course of SOC development, from a global to a differentiated (tripartite) construct; qualitative methods may be useful to supplement extant knowledge about the role and development of ISR among young adolescents."

Page 105: Repalced the word "proposes" with "proposed" so that the sentence reads, "Eccles (2009) proposed that individuals are more likely to select tasks or roles for which they have high expectations of success."

Page 105: Replaced the word "such" with "these" and the word "future" was removed so that the sentence reads, "In short, research on future orientation, future mindedness, and future selves suggests that these constructs may be linked to how youth select goals."

Page 105: Removed the phrase "There is some claim that" so that the sentence reads, "A stereotyped belief about youth is that, in general, they are shortsighted in regard to their futures (Steinberg et al., 2009)."

Page 105: Removed the words "Poster Values" so that the sentence reads, "Data were derived from the first wave of a process evaluation of the Inspire>Aspire: Global Citizens in the Making program, implemented in Scottish schools in the 2014/2015 academic year."

Page 105: Repalced the word "involves" with "included" and removed the word "the" so that the sentences read, "Only data from the first wave of the Inspire>Aspire process evaluation were available, although the project included a one-year, two-wave evaluation. Participants were drawn from five schools, with two classes participating from each school ( $N=10$ classes). All youth in participating classes were invited to complete a survey."

Page 106: Replaced the word "student's" with "students"' so that the sentence reads, "Seventeen interview questions were devised to reflect SOC skills, including hopes and fears, and students' activities and goals (Oyserman \& Markus, 1990)." 
Correction to: MacDonnell. JYD, 10(3) 2015.

Page 107: Removed the word "the" twice so that the sentence reads, "Data analysis consisted of three steps: 1 . regression analysis of the relationship between ISR and beliefs about the chances of achieving future aspirations (to address Hypothesis 1); 2. coding of qualitative interviews; and 3. synthesis of quantitative and qualitative findings (to address Hypotheses 2 and 3)."

Page 109: Replaced the word "findings" with "results" so that the sentence reads, "Consistent with this finding, results from the present study indicated that compensation and optimization were always coded at the same location within interview transcripts (the same quote was simultaneously coded for both optimization and compensation)."

Page 109: Removed the word "is" so that the sentence reads, "In another example a student said, ". . . what I've thought is if I get on with my work and don't listen to other people in the class that are trying to distract me, then I will focus on my work and won't be able to get as excitable," the student identified the barrier (distraction), and made a plan, focusing [Optimization], to counteract the barrier [Compensation]."'"

Page 110: Repalced the word "can" with "cannot" so that the sentence reads, "ISR appeared to be manifested among young adolescents in ways that quantitative measures alone cannot detect."

Page 111: Replaced the word "depict" with "detect" so that the sentence reads, "Current qualitative measures of ISR may not be able to adequately detect ISP among young adolescents.

Page 114: An acknowledgemnt of funding was added to the end.

Throughout, the accent was removed from all references to Gestsdottir.

\section{Full Text Original Article}

http://dx.doi.org/10.5195/jyd.2015.11 